\title{
Determinants of Multimethod Contraceptive Use in a Sample of Adolescent Women Diagnosed with Psychological Disorders
}

\author{
Delia L. Lang, 1, 2 Jessica M. Sales, ${ }^{1,2}$ Laura F. Salazar, 1, 2 Ralph J. DiClemente, ${ }^{1,2}$ \\ Richard A. Crosby, ${ }^{3}$ Larry K. Brown, ${ }^{4}$ and Geri R. Donenberg ${ }^{5}$ \\ ${ }^{1}$ Department of Behavioral Sciences and Health Education, Rollins School of Public Health, Emory University, Atlanta, \\ GA 30322, USA \\ ${ }^{2}$ Center for AIDS Research, Emory University, GA 30322, Atlanta, USA \\ ${ }^{3}$ College of Public Health, University of Kentucky, Lexington, KY 40536-0003, USA \\ ${ }^{4}$ Department of Psychiatry, Brown University, Providence, RI 02912, USA \\ ${ }^{5}$ Department of Psychology, University of Illinois at Chicago, Chicago, IL 60607, USA
}

Correspondence should be addressed to Delia L. Lang, dlang2@emory.edu

Received 14 April 2011; Revised 25 June 2011; Accepted 28 July 2011

Academic Editor: Tessa Madden

Copyright ( 2011 Delia L. Lang et al. This is an open access article distributed under the Creative Commons Attribution License, which permits unrestricted use, distribution, and reproduction in any medium, provided the original work is properly cited.

\begin{abstract}
Objective. Despite recommendations for concurrent use of contraceptives and condoms to prevent unintended pregnancy and STIs, multimethod contraceptive use among women is poor. This study examined individual-, interpersonal-, and environmental-level factors that predict multimethod use among sexually active adolescent women diagnosed with psychological disorders. Methods. This multisite study analyzed data from 288 sexually active adolescent women who provided sociodemographic, psychosocial, and behavioral data related to birth control and condom use. Results. $34.7 \%$ of the participants reported multimethod use in the past three months. Controlling for empirically and theoretically relevant covariates, a multivariable logistic regression identified selfefficacy, multiple partners, pregnancy history, parental communication, parental norms about sex, and neighborhood cohesion as significant predictors of multimethod use. Conclusions. While continued targeted messages about multi-method contraceptive use are imperative at the individual level, an uptake in messages targeting interpersonal- and environmental-level factors such as adolescents' parents and the broader community is urgently needed.
\end{abstract}

\section{Introduction}

Sexually transmitted infections (STIs) and unintended pregnancy are two significant public health issues that continue to affect adolescent women in the US today. Current estimates by the Centers of Disease Control and Prevention (CDC) suggest that $25 \%$ of adolescent women in the US have an STI [1], a prevalence twice as high as that among adolescent men of the same age [2]. Similarly, an estimated $82 \%$ of adolescent pregnancies are unintended despite widespread accessibility of safe, effective, and affordable contraceptive technology [3]. While a national decline in unintended pregnancies among adolescent women between 1991 and 2009 has been documented, the US continues to have higher rates of unintended teen pregnancies compared to other developed nations, particularly among adolescents residing in southern states [4].
Data on the prevalence of STIs and unintended pregnancy among adolescent women diagnosed with psychological disorders are largely lacking, although extant research among adolescents demonstrates an association between mental illness and high-risk sexual behavior including early initiation of sexual activity, sex with multiple partners, and unprotected sex [5-11]. Results from these studies suggest that this vulnerable population is at great risk for acquiring STIs including HIV as well as experiencing unintended pregnancy.

Adolescents living with psychological disorders are characterized by a unique profile of antecedent factors covering the spectrum of individual-, interpersonal- and environmental-level factors that contribute to their engaging in high-risk sexual behaviors and risk for STI/HIV infection. These factors include personal attributes (e.g., impulsivity, self-destructive behaviors, cognitive impairment, substance 
use, and poor judgment), family context (e.g., parental attitudes and behavior, parent-adolescent communication, parental monitoring, and discipline), peer and partner relationships (e.g., relationship concerns, peer influence, and partner communication), and environmental context (e.g., poverty) [12-17]. While the aforementioned studies have associated this risk profile with elevated exposure to STI/HIV infection, a similar risk profile may also result in unintended pregnancy among adolescent women seeking mental health services, although no studies to date have established this association.

Due to the prevalence of STIs and unintended pregnancies among youth, professional organizations such as the CDC, American Medical Association, American Academy of Pediatrics, and the American College of Obstetrics and Gynecology have recommended dual protection strategies toward the prevention of both STIs/HIV and unintended pregnancy [18-20]. Despite these recommendations, studies have demonstrated that dual-protection is not a commonly used strategy. For example, data from the Youth Risk Behavior For example, data from the Youth Risk Behavior Survey suggest that only $6.6 \%$ of young women surveyed used both a condom and oral contraception at their last sexual intercourse [21]. Similarly, data from the National Survey of Family Growth suggest that $8.5 \%$ of adolescent women reported the same dual-protection method of condom use and oral contraception in the previous 30 days [22]. However, among a sample of African-American adolescent women, $13.5 \%$ reported using dual protection [23].

Correlates of dual-protection use have been investigated by few studies showing that, among adolescent men and women between the ages of 14 and 22, younger AfricanAmerican adolescents who communicated with their parents about HIV-related issues were more likely to report dualprotection use $[21,22]$. Among low-income, minority, urban adolescent African-American women, those with a history of STIs who reported concerns about both pregnancy and HIV infection were also more likely to report dual-protection use [23]. Finally, in a recent study investigating correlates of dualprotection use in an array of contextual influences including individual-, interpersonal-, and community-level factors, results suggest that lower impulsivity, fearful relationship style, and fear of condom negotiation as well as higher selfesteem, social support, and partner communication selfefficacy were positively associated with dual-protection use [24]. No studies to date have investigated factors associated with dual-protection or multimethod contraceptive use among adolescent women seeking psychological services. The distinction between dual-protection and multimethod use suggests that the former category includes those who use dual methods concurrently, while the latter category includes those who use multiple contraceptive methods, but not necessarily concurrently.

The current study examines the prevalence of multimethod use as well as individual, interpersonal, and environmental factors associated with multimethod use among a sample of urban adolescent females seeking psychological services at the time of the study.

\section{Methods}

2.1. Participants. This is a substudy of a larger multisite family-based randomized clinical trial designed to evaluate the efficacy of an intervention to reduce HIV risk behaviors and STIs while enhancing HIV-preventive psychosocial and structural factors among adolescents diagnosed with psychological disorders. Adolescents were eligible if they were between the ages of 13 and 18, received a clinician-based psychological diagnosis along the externalizing-internalizing spectrum of disorders, received in- or out-patient mental health treatment at one of the study recruitment sites, lived with a parent or guardian who was also willing to participate in the study, and provided informed consent. Externalizing disorders include those that manifest in one's outward behavior (e.g., conduct disorder, oppositional defiant disorder), while internalizing disorders include those that manifest in terms of one's thoughts and feelings (e.g., depression, anxiety). Adolescents diagnosed with schizophrenia and other psychotic disorders were excluded. Additionally, adolescents were excluded if they had a history of sexually aggressive behavior (i.e., perpetrators of sexual assault or molestation), were currently pregnant, were known to have tested positive for HIV, or had cognitive deficits precluding them from completing the assessment independently or participating in group activities. Participants were enrolled in the study at three recruitment sites: Brown University, Providence, Rhode Island, University of Illinois, Chicago, and Emory University, Atlanta, Georgia. Clinics and hospitals providing mental health services to adolescents served as recruitment sites. Of 1102 adolescents who met eligibility criteria, 891 (81\%) agreed to participate and subsequently completed baseline assessments. Of the 891 participants, 288 (32.3\%) were sexually active females who completed baseline assessment prior to randomization in the HIV trial and comprised the sample analyzed in the current study. The remaining 603 participants were either male or sexually inexperienced females and were excluded from the current analyses. The Institutional Review Boards at Brown University, University of Illinois, Chicago, and Emory University approved the study protocol.

2.2. Procedures. Adolescents and parents completed an audio-assisted computerized interview at baseline. The adolescent interview assessed sociodemographic characteristics, sexual behavior patterns, and psychosocial characteristics as well as psychological symptomology. The parent interview assessed sociodemographic characteristics, parent norms about sexual behavior, and variables addressing the frequency of parent-adolescent interactions such as communication about sex. On average, interviews were 90 minutes in duration for teens and parents independently.

\subsection{Measures}

Multimethod Use. Participants were asked to identify on a list of commonly used birth control methods the one(s) they utilized in the previous 3 months: male condom, pill, diaphragm, cervical cap, gels/creams/suppositories or foams, 
Depo-Provera, and other (not further identified). Those who reported condom use and at least one other birth control method were categorized as multimethod users; those who reported using no birth control and/or only one birth control method were categorized as non-multimethod users.

Participants' age, race, ethnicity, current relationship status, and history of pregnancy were collected from adolescent participants. Family income and parent marital status were collected from parent participants.

\section{Individual-Level Measures}

Sex Partner Variables. Adolescent participants were asked how many sexual partners they had in the past 3 months. Those reporting two or more partners in the past 3 months were categorized as having multiple partners. Additionally, participants were asked whether or not they were in a current relationship with a sex partner.

Condom Use Self-Efficacy. Adolescents' self-efficacy for condom use was assessed using a 13-item scale that included items such as "How confident do you feel that you could use a condom when your partner doesn't want to?" or "How confident do you feel that you could use a condom with a new partner?" [25]. Answer options ranged from 1 (very sure I could) to 4 (very sure I could not); these responses were reverse coded such that higher scores on the condom use self-efficacy scale suggest higher perceived self-efficacy for condom use. Responses may range from 13 to 52. Cronbach's alpha reliability for this scale was .93, indicating a high level of internal consistency.

\section{Interpersonal-Level Measures}

Sexual Communication with Parent. The Miller Sexual Communication scale was used to assess the frequency of communication between parents and adolescents with regard to 6 areas including initiation of sex, contraception, condom use, transmission of HIV/AIDS, peer pressure regarding sexual behavior, and selection of sexual partner [26, 27]. Parents were asked to indicate how frequently these topics were discussed with their adolescent daughter in the past 3 months with answer options including 1 (never), 2 (once), 3 (a few times), and 4 (more than 3 times). Parent responses to the six areas of communication were summed for a total communication frequency score with higher scores suggesting more frequent communication. Responses may range from 6 to 24. Cronbach's alpha reliability for this scale was .85 , indicating a high level of internal consistency.

Parental Norms about Sex. Adolescents' perceptions of parents' degree of approval of the adolescent's sexual activity was assessed with this 7-item scale [28]. Sample items include "My parents think it is ok to have sex after one or two dates" and "My parents think it is ok to have sex with the person I love." Answer options ranged from 1 (very true) to 5 (very false) with a possible range of score from 7 to 35 . Cronbach's alpha reliability for this scale was .75 , indicating an adequate level of internal consistency.

\section{Environmental-Level Measures}

Neighborhood Cohesion. Neighborhood cohesion was assessed using a 6-item scale assessing whether adolescent respondents (1) visited neighbors, (2) could go to their neighbors for advice, (3) regularly talked to people in their neighborhood, (4) knew people's names, (5) felt comfortable asking to borrow things, and (6) felt comfortable asking neighbors to watch their home [29, 30]. Answer options ranged from 1 (strongly disagree) to 5 (strongly agree). Cronbach's alpha reliability for this scale was .88, indicating a high level of internal consistency.

2.4. Statistical Analysis. First, descriptive analyses were conducted to obtain means, standard deviations, and proportions for relevant sociodemographic variables. Additionally, bivariate analyses consisting of chi-square and independent samples $t$-tests were performed to examine the associations between multimethod and non-multimethod use and sociodemographic variables as well as to identify potential covariates. Finally, a multivariable logistic regression model was conducted to explore whether individual-, interpersonal-, and environmental-level factors predicted multimethod use after controlling for confounders. Data were analyzed using PASW 18.

\section{Results}

A total of 288 adolescent women participated in this study with a mean age of $15.29(\mathrm{SD}=1.26$; range $13-18)$. Onethird of parents $(n=96)$ reported being married, and approximately 59\% $(n=159)$ of families reported an annual income of less than $\$ 30,000$. Nearly $31.0 \%(n=89)$ of families self-identified as Caucasian, $54.5 \%(n=157)$ as African American, $12.5 \%(n=36)$ as Hispanic, and $2 \%$ $(n=6)$ as other. Among parents, $18.1 \%(n=52)$ had not completed high school. Mental disorders represented in this sample are as follows: oppositional defiant disorder (75.8\%), ADHD (56.3\%), conduct disorder (49.6\%), generalized anxiety disorder $(42.4 \%)$, major depression $(41.3 \%)$, mania $(29.7 \%)$, posttraumatic stress disorder $(27.1 \%)$, and hypomania $(26.9 \%)$. These rates represent dual diagnoses, therefore will not add up to $100 \%$. Among adolescent participants, $57.6 \%(n=166)$ reported having a current sex partner, and $16.2 \%(n=46)$ reported a pregnancy in the past. Finally, 34.7\% $(n=100)$ of adolescent participants reported multimethod use, while 50\% $(n=144)$ used only one form of protection, and $15.3 \%$ (44) used no protection at all.

Descriptive statistics as well as differences between multimethod and non-multimethod users are presented in Table 1. Of these, adolescent age, ethnicity, household income, parent marital status, and adolescent current relationship status were statistically related to multimethod use at $P \leq .20$ level and were therefore included as 
covariates in the multivariable logistic regression model [31]. Although race was not associated with multimethod use at the bivariate level $(P=.68)$, we controlled for this variable in our multivariable model predicting multimethod use outcome based on the prior literature suggesting that African-American adolescent women had higher rates of dual-protection use compared to other groups [23]. Bivariate associations between individual-, interpersonal-, and environmental level factors and multimethod use are presented in Table 2.

Results of the multivariable logistic regression model are presented in Table 3. After controlling for covariates, significant predictors of multimethod use emerged among all three contextual levels of analysis. Among individuallevel predictors, with each unit increase in condom use selfefficacy, adolescent women were $7 \%$ more likely to report multimethod use $(P=.004)$. Additionally, participants who reported multiple sex partners were nearly three times more likely to report multimethod use compared to participants reporting a single sex partner $(P=.011)$. Finally, pregnancy was a marginally significant predictor suggesting that those with a history of pregnancy were 59\% less likely to report multimethod use $(P=.052)$. Neither race nor ethnicity was significantly related to multimethod use. Among interpersonal-level predictors, with each unit increase in communication about sex (as reported by the parent), adolescent women were 3\% less likely to report multimethod use $(P=.028)$. Moreover, for each unit increase in positive parental norms about sex, adolescent women were nearly $8 \%$ more likely to report multimethod use $(P=.014)$. Finally, the single environmental predictor examined in this study was significant, suggesting that adolescent women residing in cohesive neighborhood environments were nearly twice as likely to report multimethod use compared to those residing in less cohesive neighborhood environments $(P=.041)$.

\section{Discussion}

The prevalence of multimethod use among this sample of adolescent women was nearly 35\%, which is higher compared to rates reported elsewhere in the literature [2123]. This may be a function of the way in which multimethod use was measured in this study, that is, by assessing contraceptive behaviors within the past 3 months rather than assessing concurrent use at last intercourse. Alternatively, the higher rate of multimethod use observed this sample of adolescent women receiving mental health treatment may also be a function of greater exposure and access to hormonal contraception through ongoing and regular contact with prescribing mental health and primary care professionals.

Another departure from the extant literature is that in this sample age was not significantly related to multimethod use $(P=.818)$. This is not altogether surprising given that previous research may have not included a host of contextual influences in models examining multimethod use. Our results suggest that other factors are more important in determining whether female adolescents use multiple contraceptives rather than "being older," and it is possible that, in previous studies, age may have been a proxy for some of these factors (e.g., having multiple partners). Specifically, our study identified factors associated with multimethod use at three contextual levels: individual, interpersonal, and environmental. First, at the individual level, adolescent women receiving psychological services who had a history of pregnancy were marginally less likely to report multimethod use than those without a history of pregnancy. The prior literature has consistently shown that four risk factor domains are associated with repeat teen pregnancy: disadvantaged socioeconomic background, single family household, psychological and emotional instability manifested in aggressive behavior, and exposure to chaotic environments and risky peer networks (e.g., violence and substance use) [32-38]. The current sample of adolescent women is characterized by a similar pattern of risk factors. Specifically, adolescent women in this study are particularly disadvantaged by virtue of their psychological and emotional disorders, with oppositional defiant disorder, ADHD, and conduct disorder being the most prevalent. These disorders are largely characterized by aggression, antisocial behaviors, and attention problems, all of which are documented risk factors for repeat teen pregnancy.

Having multiple partners significantly predicted multimethod use, suggesting that although adolescent women may understand the risk associated with having multiple partners, those with single partners may feel unduly protected in their relationship with one sex partner, thus deciding against multimethod use. This is consistent with prior findings suggesting that condom use declines as relationships become more serious and exclusive [39-42]. In fact, the literature suggests that among adolescents, it takes less than one month for condom use to decline to levels observed among wellestablished, long-term relationships [43]. As such, education and prevention messages regarding multimethod use should particularly focus on adolescent women reporting monogamous relationships in addition to continuing to address the risk of having multiple partners.

Finally, at the individual level, condom use self-efficacy was a significant predictor of multimethod use. Previous research suggests that among adolescents who feel confident in their condom use skills, consistent condom use increases [44-46]; however, fewer studies have assessed whether selfefficacy predicts contraceptive use beyond condoms. Findings from one such study suggest that contraceptive selfefficacy, while not predicting condom use specifically, was a significant predictor of contraceptive use in general among adolescent females [47]. Even though the current study measured condom use self-efficacy rather than contraceptive self-efficacy, our results corroborate this previous finding. It may be that self-efficacy in one sexually related domain such as using condoms may generalize to other forms of contraception.

Among interpersonal-level factors, an unexpected result suggests that, based on parent report, more frequent communication about sex with their adolescent daughters (including sex, condoms, contraception, HIV/AIDS, peer pressure, and sexual partner selection) was related to less multimethod use. Previous research has shown that parental communication about sex positively impacts sexual risk behaviors and often 
TABLE 1: Characteristics of multimethod and non-multimethod users.

\begin{tabular}{|c|c|c|c|c|c|}
\hline & \multicolumn{2}{|c|}{ Multimethod users $(n=100)$} & \multicolumn{2}{|c|}{ Non-multimethodusers $(n=188)$} & \multirow{2}{*}{$P$} \\
\hline & Mean (SD) & $N(\%)$ & Mean (SD) & $N(\%)$ & \\
\hline \multicolumn{6}{|l|}{ Sociodemographic factors } \\
\hline Age of adolescent & $15.08(1.22)$ & & $15.40(1.27)$ & & .038 \\
\hline Race & & & & & .680 \\
\hline Caucasian & & $30(30.0)$ & & $59(31.4)$ & \\
\hline African American & & $58(58.0)$ & & $99(52.7)$ & \\
\hline Other & & $3(3.0)$ & & $3(1.6)$ & \\
\hline Ethnicity & & & & & .190 \\
\hline Hispanic & & $9(9.0)$ & & $27(14.4)$ & \\
\hline Family income & & & & & .190 \\
\hline$\leq 30 \mathrm{~K} /$ year & & $60(64.5)$ & & $99(56.3)$ & \\
\hline$>30 \mathrm{~K} /$ year & & $33(35.5)$ & & $77(43.8)$ & \\
\hline Parent marital status & & & & & .161 \\
\hline Married/remarried & & $28(28.0)$ & & $68(36.2)$ & \\
\hline Single parent & & $72(72.0)$ & & $120(63.8)$ & \\
\hline $\begin{array}{l}\text { Adolescent current sex } \\
\text { partner }\end{array}$ & & & & & .001 \\
\hline Yes & & $72(72.0)$ & & $94(50.0)$ & \\
\hline No & & $28(28.0)$ & & $94(50.0)$ & \\
\hline
\end{tabular}

TABLE 2: Bivariate associations between study variables and multimethod use and non-use.

\begin{tabular}{|c|c|c|c|c|c|}
\hline & \multicolumn{2}{|c|}{ Multimethod users $(n=100)$} & \multicolumn{2}{|c|}{ Non-multimethod users $(n=188)$} & \multirow{2}{*}{$P$} \\
\hline & Mean (SD) & $N(\%)$ & Mean (SD) & $N(\%)$ & \\
\hline \multicolumn{6}{|l|}{ Individual level factors } \\
\hline Condom use self-efficacy & $47.34(5.38)$ & & $43.47(10.19)$ & & .001 \\
\hline Multiple sex partners & & & & & .002 \\
\hline Yes & & $30(30.0)$ & & $27(14.7)$ & \\
\hline No & & $70(70.0)$ & & $157(85.3)$ & .189 \\
\hline \multicolumn{6}{|l|}{ Pregnancy history } \\
\hline Yes & & $12(12.2)$ & & $34(18.3)$ & \\
\hline No & & $86(87.8)$ & & $152(81.7)$ & \\
\hline \multicolumn{6}{|l|}{ Interpersonal level factors } \\
\hline Sexual communication & $8.45(10.11)$ & & $10.11(10.12)$ & & .187 \\
\hline Parental norms about sex & $26.56(5.64)$ & & $24.28(6.25)$ & & .003 \\
\hline \multicolumn{6}{|l|}{ Environmental level factors } \\
\hline Neighborhood cohesion & & & & & .007 \\
\hline Low cohesion & & $47(48.0)$ & & $120(64.5)$ & \\
\hline High cohesion & & $51(52.0)$ & & $66(35.5)$ & \\
\hline
\end{tabular}

mitigates the effect of peer norms on adolescents' sexual risk behaviors [48-50]. Adolescents whose parents talk to them frequently and openly about sex also tend to use condoms more often and have fewer sexual partners thereby reducing their risk for STIs/HIV [48, 49, 51]. Yet, some research suggests that these protective effects may be mitigated for adolescents who are already sexually active [49]. Although this study measured the frequency and general content area of communication with adolescents, we did not measure the quality of the interactions nor the specific messages that were related to the adolescents within each content area. It may be possible that for our sample of adolescent women, who already experienced their sexual debut, some aspect of the communication process, either the style or the parental attitudes toward sex and contraception, could have contributed to the reversal of a protective effect. In fact, the current study also found a significant effect for parental norms about sex, suggesting that adolescents whose parents reported more positive attitudes toward sex were more likely to report multimethod use. Thus, it is feasible that more negative parental attitudes toward sex may interject a negative tone or more negative messages in 
TABle 3: Multivariable associations between individual-, interpersonal- and environmental level factors and multimethod use.

\begin{tabular}{lccc}
\hline & $\begin{array}{c}\text { Prevalence } \\
\text { ratio }\end{array}$ & AOR $^{\mathrm{a}}$ & $\begin{array}{c}95 \% \text { conf. } \\
\text { interval }\end{array}$ \\
\hline Individual level factors & $\mathrm{n} / \mathrm{a}$ & 1.07 & $1.02-1.12$ \\
$\quad$ Condom use self-efficacy & 0.49 & 2.87 & $1.27-6.48$ \\
$\quad$ Multiple partners & 1.49 & 0.41 & $0.17-1.00$ \\
$\quad \begin{array}{l}\text { Pregnancy history } \\
\text { Interpersonal level factors }\end{array}$ & $\mathrm{n} / \mathrm{a}$ & 0.97 & $0.94-0.99$ \\
$\quad \begin{array}{l}\text { Sexual communication } \\
\text { Parental norms about }\end{array}$ & $\mathrm{n} / \mathrm{a}$ & 1.08 & $1.02-1.14$ \\
$\quad$ sex & & & \\
Environmental level factors & & 1.91 & $1.03-3.55$ \\
$\quad$ Neighborhood cohesion & 1.35 & & \\
\hline
\end{tabular}

adjusted odds ratio using non-multimethod users as the referent category; models are controlling for adolescent age, race, ethnicity, household income, parent marital status, and adolescent current relationship status.

Model fit: $\chi^{2}=54.30 ; P=.001$.

parental communication to adolescents. As these negative messages then become reinforced with increased frequency in communication, a reduction in multimethod use may result.

Finally, neighborhood cohesion was a significant environmental-level factor associated with multimethod use suggesting that adolescent women living in a more cohesive environment, characterized by positive social contact and familiarity with neighbors, are nearly twice as likely to report multimethod use compared to adolescents residing in less cohesive environments. The mechanism by which neighborhood cohesion acts to increase condom use and other forms of contraception is unknown. Prior studies have suggested that a cohesive neighborhood environment may offer support to its adolescent residents in the form of caring, tolerance, and respect. In turn these characteristics may impact an adolescent's sense of self [51]. Research assessing the associations between social dynamics, sense of self, and health outcomes supports the assertion that social disorder can shape an individual's self-concept and subsequently can influence that individual's drug use and sexual risk taking [52, 53]. Among adolescent women coping with psychological disorders, the positive impact of neighborhood support and cohesion may be particularly salient. Further research is necessary to uncover the underlying mechanisms by which neighborhood cohesion is associated with various protective sexual health outcomes including condom use and multimethod use, particularly among adolescent women with psychological disorders.

4.1. Limitations. Several limitations to this study need to be acknowledged. First, the generalizability of the findings is limited to (a) adolescents meeting the specific criteria for inclusion in the randomized clinical trial and (b) the three geographic regions of the county from which the data are obtained. Second, data included in the current analyses were obtained through self-report and may reflect social desir- ability bias. Third, the multimethod use measure assessed condom use and one other birth control method. This could include a hormonal method such as the birth control pill or some other type of barrier method such as the diaphragm. The various possible combinations of multiple methods were not explored in this study as this would have significantly restricted the sample size available for analysis. Fourth, the multiple methods of contraceptive use were assessed over the previous 3 months with no assessment of concurrent use. Finally, length of relationship may play a role in adolescents' willingness to utilize contraception and should be assessed in future studies.

\section{Conclusion}

Understanding multilevel factors that predict multimethod contraceptive use among adolescent women with psychological disorders is crucial both in terms of clinical practice as well as in the design of STI/HIV and pregnancy prevention programs. Research should further investigate the specific factors that contribute to this protective behavior. Mental health as well as primary care providers should continue to focus on addressing issues of multimethod as well as dual-protection use with their female adolescent population. Furthermore, while public health professionals have historically focused on designing and implementing STI/HIV prevention programs separately from pregnancy prevention programs, given the high rates of STIs and unintended pregnancy among adolescent women, especially among those with compromised psychological states, it is advisable to design programs that target both epidemics concurrently through programs that incorporate modifiable factors at the individual, interpersonal, and environmental levels.

\section{Acknowledgments}

This research was supported by the National Institute of Mental Health Grant R01 MH63008 to Rhode Island Hospital (Principal Investigator: Larry K. Brown). This project was made possible through the dedicated efforts of the Project STYLE Study Group whose members are listed here in alphabetical order: Principal Investigators: Larry K. Brown (Rhode Island Hospital), Ralph DiClemente (Emory University), and Geri Donenberg (University of Illinois at Chicago); Site Investigators: Chinmayee Barve (University of Illinois at Chicago), Richard Crosby (Emory University), Wendy Hadley (Rhode Island Hospital), Delia Lang (Emory University), Celia Lescano (Rhode Island Hospital), and Cami McBride (Rosalind Franklin University of Medicine and Science); Consultants: Nancy Beausoleil (Rhode Island Hospital), Angela Caliendo (Emory University), David Pugatch (Rhode Island Hospital), and Ron Seifer (Rhode Island Hospital); Project Coordinators: Katelyn Affleck, Catherine Barber, Renee Johnson, Harrison Kell, Erika Litvin, and Jonathon Thompson (Rhode Island Hospital); Gloria Coleman, Emily Hasselquist, Chisina Kapungu, and Charu Thakral (University of Illinois at Chicago); Cara Averhart, Wayne Baudy, Emily Higgins, and Ana Massey (Emory University). 


\section{References}

[1] Centers for Disease Control and Prevention, "HIV/AIDS surveillance report, 2002: year end edition," Tech. Rep., US Department of Health and Human Services, Atlanta, Ga, USA, 2003.

[2] R. Crosby, J. S. Leichliter, and R. Brackbill, "Longitudinal prediction of sexually transmitted diseases among adolescents: results from a national survey," American Journal of Preventive Medicine, vol. 18, no. 4, pp. 312-317, 2000.

[3] L. B. Finer and S. K. Henshaw, "Disparities in rates of unintended pregnancy in the United States, 1994 and 2001," Perspectives on Sexual and Reproductive Health, vol. 38, no. 2, pp. 90-96, 2006.

[4] K Pazol, L. Warner, L. Gavin et al., "Centers for Disease Control and Prevention. Vital signs: teen pregnancy, United States, 2001-2090," Morbidity and Mortality Weekly Report, vol. 60, no. 13, pp. 414-420, 2011.

[5] R. E. Booth and Y. Zhang, "Conduct disorder and HIV risk behaviors among runaway and homeless adolescents," Drug and Alcohol Dependence, vol. 48, no. 2, pp. 69-76, 1997.

[6] S. Ramrakha, A. Caspi, N. Dickson, T. E. Moffitt, and C. Paul, "Psychiatric disorders and risky sexual behaviour in young adulthood: cross sectional study in birth cohort," British Medical Journal, vol. 321, no. 7256, pp. 263-266, 2000.

[7] E. A. Whitmore, S. K. Mikulich, K. M. Ehlers, and T. J. Crowley, "One-year outcome of adolescent females referred for conduct disorder and substance abuse/dependence," Drug and Alcohol Dependence, vol. 59, no. 2, pp. 131-141, 2000.

[8] L. A. Shrier, S. K. Harris, M. Sternberg, and W. R. Beardslee, "Associations of depression, self-esteem, and substance use with sexual risk among adolescents," Preventive Medicine, vol. 33 , no. 3, pp. 179-189, 2001.

[9] M. D. Smith, "HIV risk in adolescents with severe mental illness: literature review," Journal of Adolescent Health, vol. 29, no. 5, pp. 320-329, 2001.

[10] W. F. Auslander, J. Curtis McMillen, D. Elze, R. Thompson, M. Jonson-Reid, and A. Stiffman, "Mental health problems and sexual abuse among adolescents in foster care: relationship to HIV risk behaviors and intentions," AIDS and Behavior, vol. 6, no. 4, pp. 351-359, 2002.

[11] J. G. Tubman, A. G. Gil, E. F. Wagner, and H. Artigues, "Patterns of sexual risk behaviors and psychiatric disorders in a community sample of young adults," Journal of Behavioral Medicine, vol. 26, no. 5, pp. 473-500, 2003.

[12] R. J. DiClemente and L. E. Ponton, "HIV-related risk behaviors among psychiatrically hospitalized adolescents and schoolbased adolescents," American Journal of Psychiatry, vol. 150, no. 2, pp. 324-325, 1993.

[13] L. K. Brown, M. B. Danovsky, K. J. Lourie, R. J. DiClemente, and L. E. Ponton, "Adolescents with psychiatric disorders and the risk of HIV," Journal of the American Academy of Child and Adolescent Psychiatry, vol. 36, no. 11, pp. 1609-1617, 1997.

[14] G. R. Donenberg, E. Emerson, F. B. Bryant, H. Wilson, and E. Weber-Shifrin, "Understanding AIDS-risk behavior among adolescents in psychiatric care: links to psychopathology and peer relationships," Journal of the American Academy of Child and Adolescent Psychiatry, vol. 40, no. 6, pp. 642-653, 2001.

[15] G. R. Donenberg and M. Pao, "Understanding HIV/AIDS: psychosocial and psychiatric issues in youths," Contemporary Psychiatric, vol. 2, pp. 1-8, 2003.

[16] H. W. Wilson and G. Donenberg, "Quality of parent communication about sex and its relationship to risky sexual behavior among youth in psychiatric care: a pilot study," Journal of Child Psychology and Psychiatry and Allied Disciplines, vol. 45, no. 2, pp. 387-395, 2004.

[17] G. R. Donenberg and M. Pao, "Youths and HIV/AIDS: Psychiatry's role in a changing epidemic," Journal of the American Academy of Child and Adolescent Psychiatry, vol. 44, no. 8, pp. 728-747, 2005.

[18] D. W. Kaplan, R. A. Feinstein, M. M. Fisher et al., "Condom use by adolescents: committee on adolescence," Pediatrics, vol. 107, no. 6, pp. 1463-1469, 2001.

[19] K. A. Workowski and S. M. Berman, "Centers for Disease Control and Prevention. Sexually transmitted diseases treatment guidelines 2006: clinical prevention guidance," Morbidity and Mortality Weekly Report, vol. 55, no. RR-11, pp. 5-6, 2006.

[20] Faculty of Family Planning and Reproductive Health Care Clinical Effectiveness Unit, "FFPRHC guidance (October 2004) contraceptive choices for young people," Journal of Family Planning and Reproductive Health Care, vol. 30, no. 4, pp. 237-251, 2004.

[21] J. S. Santelli, C. W. Warren, R. Lowry et al., "The use of condoms with other contraceptive methods among young men and women," Family Planning Perspectives, vol. 29, no. 6, pp. 261-267, 1997.

[22] L. J. Piccinino and W. D. Mosher, "Trends in contraceptive use in the United States: 1982-1995," Family Planning Perspectives, vol. 30, no. 1, pp. 4-46, 1998.

[23] R. A. Crosby, R. J. DiClemente, G. M. Wingood et al., "Correlates of using dual methods for sexually transmitted diseases and pregnancy prevention among high-risk africanamerican female teens," Journal of Adolescent Health, vol. 28, no. 5, pp. 410-414, 2001.

[24] J. M. Sales, T. P. Latham, R. J. DiClemente, and E. Rose, "Differences between dual-method and non-dual-method protection use in a sample of young African American women residing in the Southeastern United States," Archives of Pediatrics and Adolescent Medicine, vol. 164, no. 12, pp. 11251131, 2010.

[25] D. M. Grimley, J. O. Prochaska, W. F. Velicer, and G. E. Prochaska, "Contraceptive and condom use adoption and maintenance: a stage paradigm approach," Health Education Quarterly, vol. 22, no. 1, pp. 20-35, 1995.

[26] R. Dutra, K. S. Miller, and R. Forehand, "The process and content of sexual communication with adolescents in twoparent families: associations with sexual risk-taking behavior," AIDS and Behavior, vol. 3, no. 1, pp. 59-66, 1999.

[27] K. S. Miller, R. Forehand, and B. A. Kotchick, "Adolescent sexual behavior in two ethnic minority samples: the role of family variables," Journal of Marriage and Family, vol. 61, no. 1, pp. 85-98, 1999.

[28] S. A. Baker, S. P. Thalberg, and D. M. Morrison, "Parents' behavioral norms as predictors of adolescent sexual activity and contraceptive use," Adolescence, vol. 23, no. 90, pp. 265286,1988

[29] A. J. Sheidow, D. Gorman-Smith, P. H. Tolan, and D. B. Henry, "Family and community characteristics: risk factors for violence exposure in inner-city youth," Journal of Community Psychology, vol. 29, no. 3, pp. 345-360, 2001.

[30] P. H. Tolan, D. Gorman-Smith, and D. B. Henry, "Chicago youth development study community and neighborhood measure: construction and reliability technical report," Families and Communities Research Group, University of Illinois, Chicago, Ill, USA, 2001.

[31] D. W. Hosmer and S. L. Lemeshow, Applied Logistic Regression, John Wiley and Sons, New York, NY, USA, 2000. 
[32] C. P. Crittenden, N. W. Boris, J. C. Rice, C. A. Taylor, and D. L. Olds, "The role of mental health factors, behavioral factors, and past experiences in the prediction of rapid repeat pregnancy in adolescence," Journal of Adolescent Health, vol. 44, no. 1, pp. 25-32, 2009.

[33] J. B. Hardy, N. M. Astone, J. Brooks-Gunn, S. Shapiro, and T. L. Miller, "Like mother, like child: intergenerational patterns of age at first birth and associations with childhood and adolescent characteristics and adult outcomes in the second generation," Developmental Psychology, vol. 34, no. 6, pp. 1220-1232, 1998.

[34] L. Woodward, D. M. Fergusson, and L. J. Horwood, "Risk factors and life processes associated with teenage pregnancy: results of a prospective study from birth to 20 years," Journal of Marriage and Family, vol. 63, no. 4, pp. 1170-1184, 2001.

[35] L. V. Scaramella, R. D. Conger, R. L. Simons, and L. B. Whitbeck, "Predicting risk for pregnancy by late adolescence: a social contextual perspective," Developmental Psychology, vol. 34, no. 6, pp. 1233-1245, 1998.

[36] L. J. Woodward and D. M. Fergusson, "Early conduct problems and later risk of teenage pregnancy in girls," Development and Psychopathology, vol. 11, no. 1, pp. 127-141, 1999.

[37] D. M. Fergusson and L. J. Woodward, "Teenage pregnancy and female educational underachievement," Journal of Marriage and Family, vol. 62, no. 1, pp. 147-161, 2000.

[38] R. J. Sampson and J. L. Lauritsen, "Violent victimization and offending: individual-, situational-, and community-level risk factors," in Understanding and Preventing Violence, A. J. Reiss and J. A. Roth, Eds., vol. 3 of Social Influences, National Academy Press, Washington, DC, USA, 1994.

[39] S. R. Friedman, P. L. Flom, B. J. Kottiri et al., "Consistent condom use in the heterosexual relationships of young adults who live in a high-HIV-risk neighbourhood and do not use hard drugs," AIDS Care, vol. 13, no. 3, pp. 285-296, 2001.

[40] B. A. Kotchick, A. Shaffer, R. Forehand, and K. S. Miller, "Adolescent sexual risk behavior: a multi-system perspective," Clinical Psychology Review, vol. 21, no. 4, pp. 493-519, 2001.

[41] S. J. Misovich, J. D. Fisher, and W. A. Fisher, "Close relationships and elevated HIV risk behavior: evidence and possible underlying psychological processes," Review of General Psychology, vol. 1, no. 1, pp. 72-107, 1997.

[42] A. E. Norris and K. Ford, "Sexual experiences and condom use of heterosexual, low-income African American and Hispanic youth practicing relative monogamy, serial monogamy, and nonmonogamy," Sexually Transmitted Diseases, vol. 26, no. 1, pp. 17-25, 1999.

[43] J. D. Fortenberry, W. Tu, J. Harezlak, B. P. Katz, and D. P. Orr, "Condom use as a function of time in new and established adolescent sexual relationships," American Journal of Public Health, vol. 92, no. 2, pp. 211-213, 2002.

[44] S. Ryan, K. Franzetta, and J. Manlove, "Knowledge, perceptions, and motivations for contraception: influence on teens' contraceptive consistency," Youth and Society, vol. 39, no. 2, pp. 182-208, 2007.

[45] R. Crosby, R. J. DiClemente, G. M. Wingood et al., "Correct condom application among African-American adolescent females: the relationship to perceived self-efficacy and the association to confirmed STDs," Journal of Adolescent Health, vol. 29, no. 3, pp. 194-199, 2001.

[46] R. J. DiClemente, "Psychosocial determinants of condom use among adolescents," in Adolescents and Aids: A Generation in Jeopardy, R. J. DiClemente, Ed., pp. 34-51, Sage Publications, Newbury Park, Calif, USA, 1992.
[47] M. A. Longmore, W. D. Manning, P. C. Giordano, and J. L. Rudolph, "Contraceptive self-efficacy: does it influence adolescents' contraceptive use?" Journal of Health and Social Behavior, vol. 44, no. 1, pp. 45-60, 2003.

[48] D. J. Whitaker, K. S. Miller, D. C. May, and M. L. Levin, "Teenage partners' communication about sexual risk and condom use: the importance of parent-teenager discussions," Family Planning Perspectives, vol. 31, no. 3, pp. 117-121, 1999.

[49] K. S. Miller, M. L. Levin, D. J. Whitaker, and X. Xu, "Patterns of condom use among adolescents: the impact of mother- adolescent communication," American Journal of Public Health, vol. 88, no. 10, pp. 1542-1544, 1998.

[50] D. J. Whitaker and K. S. Miller, "Parent-adolescent discussions about sex and condoms: impact on peer influences of sexual risk behavior," Journal of Adolescent Research, vol. 15, no. 2, pp. 251-273, 2000.

[51] D. Kerrigan, S. Witt, B. Glass, S. E. Chung, and J. Ellen, "Perceived neighborhood social cohesion and condom use among adolescents vulnerable to HIV/STI," AIDS and Behavior, vol. 10, no. 6, pp. 723-729, 2006.

[52] C. A. Latkin, A. D. Curry, W. Hua, and M. A. Davey, "Direct and indirect associations of neighborhood disorder with drug use and high-risk sexual partners," American Journal of Preventive Medicine, vol. 32, no. 6S, pp. S234-S241, 2007.

[53] C. A. Latkin, C. T. Williams, J. Wang, and A. D. Curry, "Neighborhood social disorder as a determinant of drug injection behaviors: a structural equation modeling approach," Health Psychology, vol. 24, no. 1, pp. 96-100, 2005. 


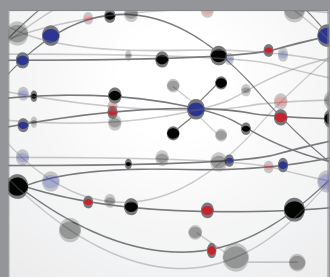

The Scientific World Journal
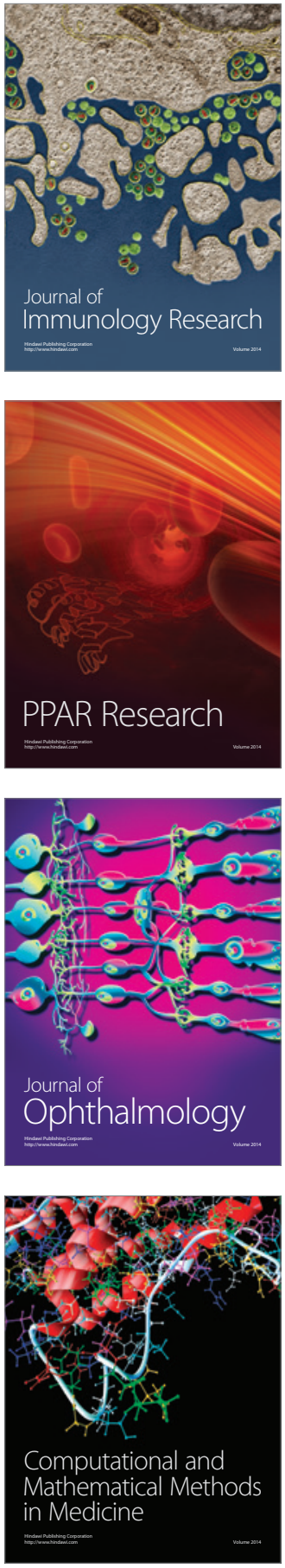

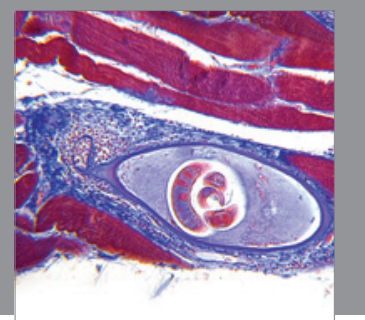

Gastroenterology

Research and Practice
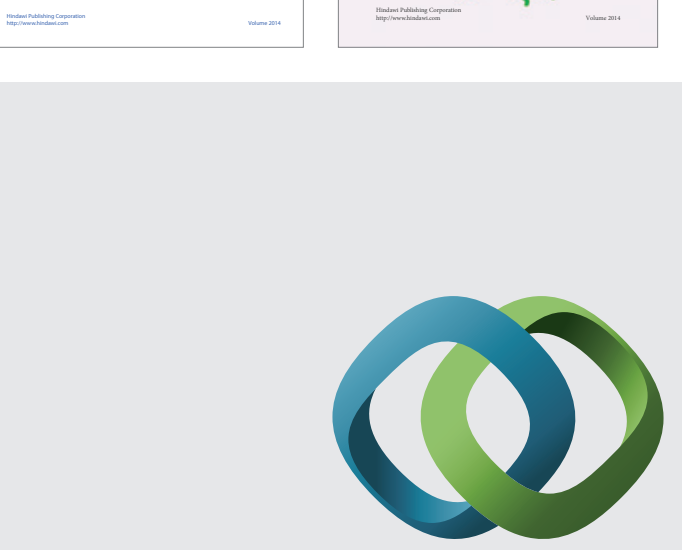

\section{Hindawi}

Submit your manuscripts at

http://www.hindawi.com
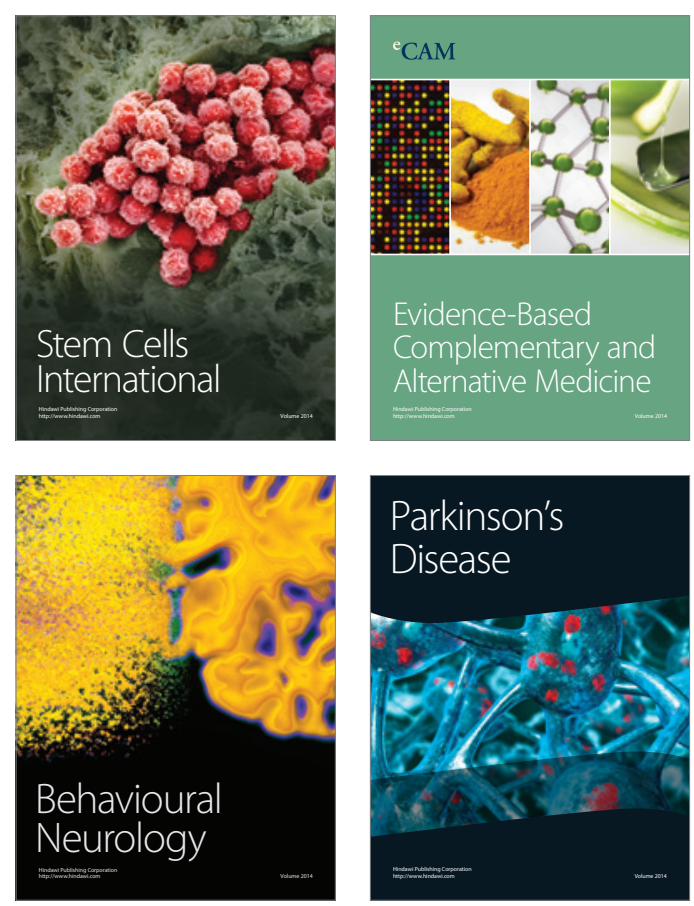

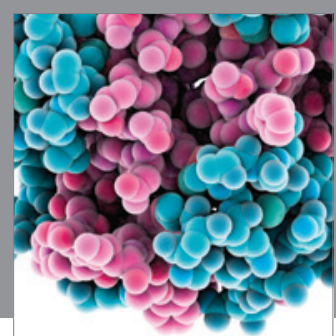

Journal of
Diabetes Research

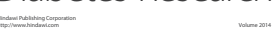

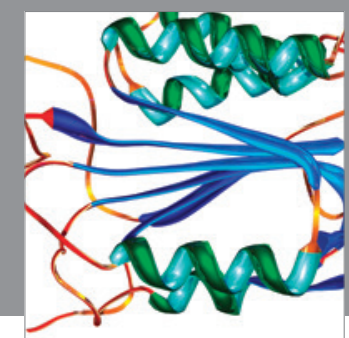

Disease Markers
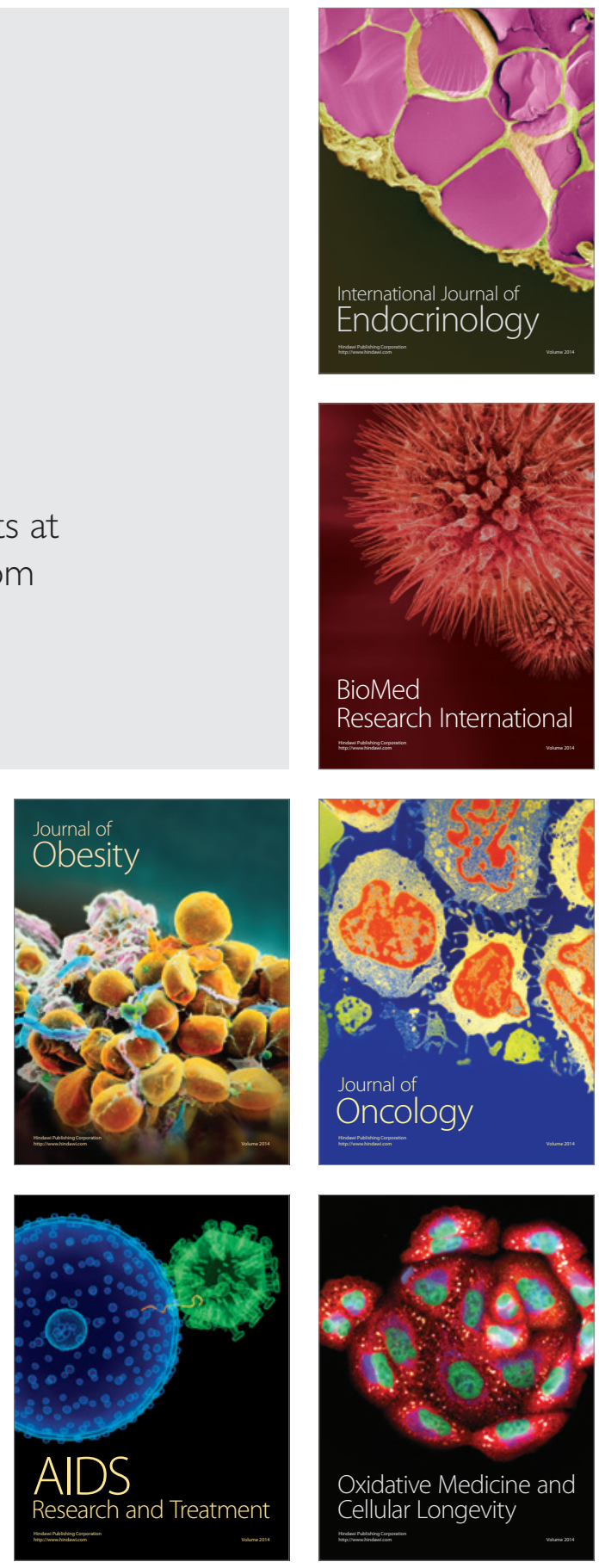